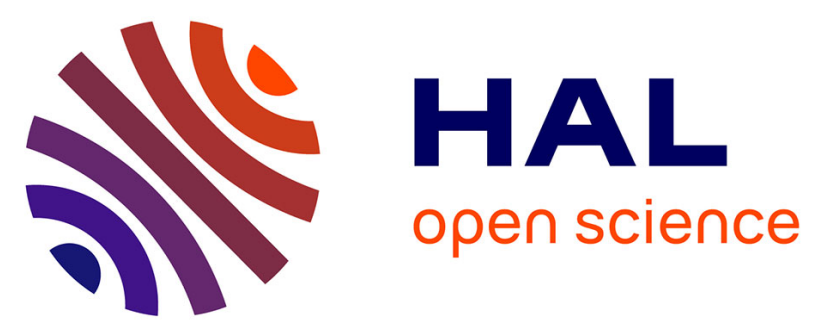

\title{
Tiny dexamethasone palmitate nanoparticles for intravitreal injection: optimization and in vivo evaluation
}

Romain Canioni, Franceline Reynaud, Thais Leite-Nascimento, Claire Gueutin, Nicolas Guiblin, Nour-Eddine Ghermani, Christine Jayat, Philippe Daull, Jean-Sébastien Garrigue, Elias Fattal, et al.

\section{To cite this version:}

Romain Canioni, Franceline Reynaud, Thais Leite-Nascimento, Claire Gueutin, Nicolas Guiblin, et al.. Tiny dexamethasone palmitate nanoparticles for intravitreal injection: optimization and in vivo evaluation. International Journal of Pharmaceutics, 2021, 600, pp.120509. 10.1016/j.ijpharm.2021.120509 . hal-03184392

\section{HAL Id: hal-03184392 \\ https://hal-centralesupelec.archives-ouvertes.fr/hal-03184392}

Submitted on 29 Mar 2021

HAL is a multi-disciplinary open access archive for the deposit and dissemination of scientific research documents, whether they are published or not. The documents may come from teaching and research institutions in France or abroad, or from public or private research centers.
L'archive ouverte pluridisciplinaire HAL, est destinée au dépôt et à la diffusion de documents scientifiques de niveau recherche, publiés ou non, émanant des établissements d'enseignement et de recherche français ou étrangers, des laboratoires publics ou privés. 
Tiny dexamethasone palmitate nanoparticles for intravitreal injection: optimization and in vivo evaluation.

Romain Canioni ${ }^{1 *}$, Franceline Reynaud ${ }^{1.2 *}$, Thais Leite-Nascimento ${ }^{1,3}$, Claire Gueutin ${ }^{1}$, Nicolas Guiblin ${ }^{4}$, Nour-Eddine Ghermani ${ }^{14}$, Christine Jayat ${ }^{5}$, Philippe Daull ${ }^{5}$, Jean-Sébastien Garrigue $^{5}$, Elias Fattal ${ }^{1}$, Nicolas Tsapis ${ }^{1 *}$

${ }^{1}$ Université Paris-Saclay, CNRS, Institut Galien Paris-Saclay, 92296, Châtenay-Malabry, France

${ }^{2}$ School of Pharmacy, Federal University of Rio de Janeiro, 21944-59 Rio de Janeiro, Brazil ${ }^{3}$ Laboratory of Pharmaceutical Nanotechnology and Drug Delivery Systems, School of Pharmacy, Federal University of Goiás, Goiânia, Brazil

4 Université Paris-Saclay, CentraleSupélec, CNRS, Laboratoire SPMS, 91190, Gif-surYvette, France

${ }^{5}$ Santen SAS, 1 Rue Pierre Fontaine, 91000 Evry, France

${ }^{*} \mathrm{R}$. Canioni and F. Reynaud equally contributed to the work.

*Corresponding author: Nicolas TSAPIS, nicolas.tsapis@universite-paris-saclay.fr

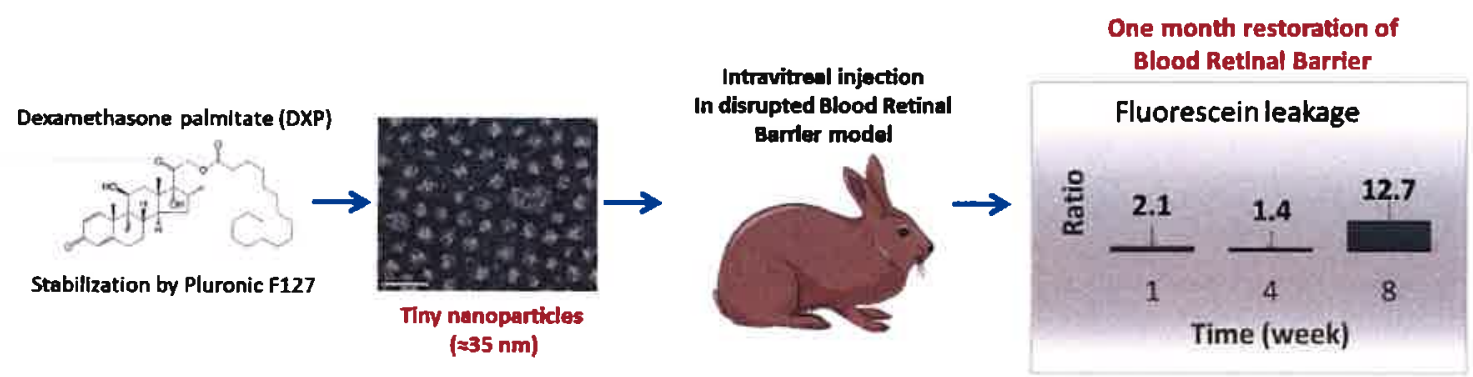




\begin{abstract}
Tiny nanoparticles of dexamethasone palmitate (DXP) were designed as transparent suspensions for intravitreal administration to treat age-related macular degeneration (AMD). The influence of three surfactants (PEG-40-stearate and Pluronic block copolymers F68 and F127) on nanoparticles size and stability was investigated and led to an optimal formulation based on Pluronic F127 stabilizing DXP nanoparticles. Size measurements and TEM revealed tiny nanoparticles (around $35 \mathrm{~nm}$ ) with a low opacity, compatible with further intravitreal injection. X-Ray powder diffraction (XRPD) and transmission electronic microscopy (TEM) performed on freeze-dried samples showed that DXP nanoparticles were rather monodisperse and amorphous. The efficacy of DXP nanoparticles was assessed in vivo on pigmented rabbits with unilateral intravitreal injections. After breakdown of the bloodretinal barrier (BRB) induced by injection of rhVEGF165 with carrier protein, DXP nanoparticles induced a restoration of the BRB 1 month after their intravitreal injection. However, their efficacy was limited in time most probably by clearance of DXP nanoparticles after 2 months due to their small size.
\end{abstract}

Keywords: dexamethasone palmitate, nanoparticles, intravitreal injection, retinal disease 


\section{INTRODUCTION}

Age-related macular degeneration (AMD) is a macular disorder that represents a leading cause of severe and irreversible visual impairment(Mitchell et al., 2018). This disease can develop in a "wet" and a "dry" form. Clinical signs which characterize both of these forms in the early stages are the formation of numerous drusen, retinal pigment epithelium (RPE) abnormalities, geographic atrophy (GA) of the RPE and the choriocapillaris, and neovascular maculopathy((AAO), 2006; Rein et al., 2009). In the dry form, the most common one (90\% of cases), visual loss is usually gradual and depends of the drusen growth in the macular area. The wet form is less frequent (10\% of cases) but more severe, and with a faster evolution. The main feature is the development of choroidal neovascularization (CNV), i.e. the formation of new abnormal blood vessels growing below the retina(Buschini et al., 2011). Without treatment, neovessels tend to form a big scar in the macular area, resulting in a dramatic decrease in central vision(Kokotas et al., 2011). Since AMD frequency increases with aging, as population is getting older, this handicapping disease will increase significantly in the next 40 years.

Corticosteroids are efficient anti-inflammatory drugs widely used for the treatment of acute or chronic eye diseases such as uveitis(Munoz-Fernandez and Martin-Mola, 2006) and could also have an important role in the management of ocular diseases involving neovascularization(Kertes and Coupland, 2005). Nevertheless, their administration by the systemic route often generates systemic and ocular toxic effects (cataract and glaucoma), and topical ocular application does not allow to reach a therapeutic level of the active principle. Periocular injections can avoid these problems, but can also breed periocular fibrosis, globe perforation and ptosis(Ferrante et al., 2004). Direct release of drugs into the vitreous is therefore required for the effective treatment of posterior segment diseases, even though repeated injections may be necessary to ensure therapeutic levels over an extended period of time(Giancipoli et al., 2018). Although used in the clinics, intraocular injections of drug solutions or suspensions(Grzybowski et al., 2019) are not totally harmless and multiple injections can increase the probability of complications like vitreous hemorrhage or retinal detachment. Furthermore, administration of drug solution leads to a local peak of concentration that can have deleterious effects(Kwak and D'Amico, 1992). Encapsulation of drugs into intravitreal implants such as Ozurdex@ is currently used in the clinics but several report show that the macroscopic implant can in some case migrate into the anterior chamber(Malclès et al., 2013; Vela et al., 2012)

Particulate drug delivery systems represents a good option to circumvent the above-cited problems(Bochot and Fattal, 2012). Whereas microparticulate systems sediment in the vitreous, nanoparticles (NPs) do not sediment, leading to a more homogeneous distribution 
in the vitreous. In addition, NPs possess the ability to be internalized within retinal cells(Bourges et al., 2003). Several studies report NPs use for intravitreal administration(de Kozak et al., 2004; Gomes dos Santos et al., 2006; Gomes Dos Santos et al., 2006; Irache et al., 2005; Kassem et al., 2007; Merodio et al., 2002). Most nanoparticulate systems proposed to encapsulate corticosteroids consist in biodegradable polymer(Gomez-Gaete et al., 2007; Gómez-Gaete et al., 2008; Ishihara et al., 2010, 2009; Kim and Martin, 2006; Sahoo et al., 2008). Among nanoparticulate polymeric systems drawbacks is their low drug loading usually below 5\%(Kumari et al., 2010) and their important drug burst release(Allen and Cleland, 1980; Allen and Cullis, 2013; Gomez-Gaete et al., 2007; Gómez-Gaete et al., 2008). To overcome these disadvantages, a recent strategy has consisted in formulating lipophilic prodrugs of corticoids such as dexamethasone palmitate (DXP) directly into NPs by using only PEGylated lipids as the only excipients(Fattal et al., 2018; Lorscheider et al., 2019b, 2019a). One obtains $150 \mathrm{~nm}$ NPs that are stable for a few weeks and do not exhibit a burst release. Unfortunately, this size range is not suitable for an intravitreal injection as suspensions were too opaque. Several surfactants compatible with an intravitreous administration and bearing polyethylene glycol (PEG) moieties were investigated to obtain DXP NPs as small as possible to avoid visual perturbation due to opacity, $100 \mathrm{~nm}$ being the acceptable upper size limit. The optimal formulation was then fully characterized and tested in vivo in a rabbit model of VEGF-induced hyperpermeability.

\section{MATERIALS AND MEthods}

\section{Materials}

Pluronic block copolymers F127, F68 and PEG-40-stearate were gifts from Croda (France). Water was purified using a RIOS/Synergy system from Millipore (France). Acetone in analytical grade and methanol for high-performance liquid chromatography (HPLC) were obtained from Carlo Erba Reagents (France). Dexamethasone palmitate (DXP) was provided by Santen SAS (France). Dexamethasone (DXM) was purchased from Chemos (Germany). All other reagents were obtained from Sigma-Aldrich (France).

\section{DXP photostability}

DXP photostability was studied as by exposing the DXP powder at $25^{\circ} \mathrm{C}$ in a clear vial to 1.2 million lux (3.5 days under UV + white light exposure followed by 9 days of white light exposure only). DXP purity was then determined before and after exposure after powder dissolution into methanol and HPLC analysis as described below. 


\section{Nanoparticles preparation}

DXP nanoparticles (NPs) were prepared by the nanoprecipitation process(Fessi et al., 1989) using the protocol described before(Lorscheider et al., 2019a) with slight modifications. Amber glassware was used throughout the whole preparation process due to DXP photodegradation (see results). The surfactant was dissolved into $200 \mathrm{~mL}$ of water placed in a $1 \mathrm{~L}$ amber pyriform flask to reach the desired concentration $(1.0,1.5$ or $2.0 \% \mathrm{w} / \mathrm{v}))$. At the same time, DXP was dissolved into $10 \mathrm{~mL}$ of acetone volumetric flask with acetone $(0.025$, 0.050 and $0.075 \% \mathrm{w} / \mathrm{v})$. The aqueous solution was heated at $60^{\circ} \mathrm{C}$, and the organic solution was injected directly into it under stirring using a syringe needle $(21 \mathrm{G})$. Acetone was then evaporated under reduced pressure using a rotary evaporator. Acetone removal was checked by ${ }^{1} \mathrm{H}$ NMR on a Bruker Avance 300 spectrometer $\left(v\left({ }^{1} \mathrm{H}\right)=300 \mathrm{MHz}\right)$. To concentrate the suspension, it was placed into a $200 \mathrm{~mL}$ ultrafiltration cell from Millipore (France), fitted up with a 100,000 Da regenerated cellulose membrane, under nitrogen pressure until the volume was reduced to $20 \mathrm{~mL}$. Finally, trehalose was added to the concentrated suspension (final concentration $0.5,1,2.5,3.5$ and $4.5 \%(\mathrm{w} / \mathrm{v})$ ) as a cryoprotectant before being frozen in liquid nitrogen and freeze-dried for $48 \mathrm{~h}$ using a CHRIST ALPHA 1-2 LD plus (France) freeze-drier.

\section{Size, zeta potential and opacity measurements}

Particle size and polydispersity index (PDI) were measured using a Malvern Zetasizer Nano ZS (Malvern Instrument, UK) based on quasi-elastic light scattering. Size measurements were performed at $20^{\circ} \mathrm{C}$, at an angle of $173^{\circ}$ to avoid multiple scattering. Results were expressed as the average of the mean diameter of the nanoparticles obtained from three measurements, following a $1 / 5(\mathrm{v} / \mathrm{v})$ dilution of a nanoparticle suspension at $8 \mathrm{mg} / \mathrm{mL} \mathrm{DXP}$ into water. The standard deviation of the size and the PDIs were also given. The dispersion was considered as monodisperse when the PDI was lower than 0.2. Zeta potential was measured using the same instrument, following the same dilution in a $1 \mathrm{mM} \mathrm{NaCl}$ solution. Suspensions were stored in amber vials at room temperature $\left(20^{\circ} \mathrm{C}\right)$ or at $4^{\circ} \mathrm{C}$ and the size of the nanoparticles was measured at T0, and after 2, 5, 9 and 15 days, when possible. Opacity measurements were performed by measuring the percentage of transmitted light at $850 \mathrm{~nm}$.

\section{Dexamethasone palmitate loading within nanoparticles}

Determination of DXP concentration in the NP suspension was performed by HPLC. A Water $^{\mathrm{TM}} 2707$ autosampler chromatographic system was employed equipped with a Waters $^{T M} 1525$ binary HPLC pump, a Waters ${ }^{T M} 2998$ photodiode array detector, and a Waters $^{\mathrm{TM}}$ Empower software. The analysis was performed at $240 \mathrm{~nm}$ using a 
SymmetryShield ${ }^{T M}$ RP18 column (5 $\mu \mathrm{m}, 250 \times 4.6$ mm; Waters, Saint-Quentin-en-Yvelines, France). Column temperature was maintained at $20^{\circ} \mathrm{C}$ using a column Heater (Model 1500 , Waters Corporation). The mobile phase involved a variable composition of solvent A (mixture of water:methanol in the $30: 70(\mathrm{v} / \mathrm{v})$ ratio $+0.1 \%$ formic acid) and solvent $B$ (mixture of water:methanol in the $8: 92(\mathrm{v} / \mathrm{v})$ ratio $+0.1 \%$ formic acid). The mobile phase was pumped through the column with a flow rate of $1.2 \mathrm{ml} / \mathrm{min}$ (Table 1). The developed method showed good linearity for low concentrations between 1 and $25 \mu \mathrm{g} / \mathrm{mL}\left(y=63627 x-8322.4\right.$; with $r^{2}=$ $0.9999)$ and for higher concentrations between 25 and $500 \mu \mathrm{g} / \mathrm{mL}(y=57297 x+70768$; with $r^{2}=0.9998$ ). Experiments were performed at least in duplicate.

Table 1: Mobile phase program for gradient elution

\begin{tabular}{cccc}
\hline Time $(\mathrm{min})$ & Flow rate $(\mathrm{mL} / \mathrm{min})$ & Solvent A (\%) & Solvent B (\%) \\
\hline 0 & 1.2 & 100 & 0 \\
5 & 1.2 & 0 & 100 \\
25 & 1.2 & 0 & 100 \\
27 & 1.2 & 100 & 0 \\
35 & 1.2 & 100 & 0 \\
\hline
\end{tabular}

\section{Osmolality measurements}

Osmolality was measured on a freezing point depression automatic micro osmometer (Type 13/13DR autocal, Roebling, Germany).

\section{$X$-Ray Powder Diffraction}

X-ray powder diffraction (XRPD) patterns were measured on a Rigaku rotating anode automated diffractometer operated at $50 \mathrm{kV}$ and $200 \mathrm{~mA}$ using $\mathrm{Cu} \mathrm{K \alpha}$ radiation. Data were collected 4 times and averaged over an angular range comprised between 1 and $60^{\circ}(2 \theta)$ with a step size of $0.02^{\circ}$ and an accumulation time of 4 s per step.

\section{Transmission Electron Microscopy}

Transmission Electron Microscopy (TEM) was performed at IMAGIF (CNRS, Gif s/Yvette, France) using a JEOL JEM-1400 microscope operating at $80 \mathrm{kV}$ with a filament current of about $55 \mu \mathrm{A}$. Suspensions of nanoparticles after ultrafiltration, freeze-drying and reconstitution with water $(0.04 \mathrm{mg} / \mathrm{mL}$ or $0.2 \mathrm{mg} / \mathrm{mL} D X P)$ were deposited $(3 \mu \mathrm{L})$ on copper grids (400 mesh) covered with a formvar-carbon film for $5 \mathrm{~min}$. Negative staining was then 
performed by adding a droplet of uranyl acetate $(2 \% \mathrm{w} / \mathrm{w})$ for $30 \mathrm{~s}$. The excess solution was blotted off using filter paper and grids were air dried before observation. Images were acquired using a postcolumn high-resolution (11 megapixels) high-speed camera (SC1000 Orius; Gatan) and processed with Digital Micrograph (Gatan) and ImageJ.

\section{In vivo experiments}

Ten pigmented rabbits ( 5 males and 5 females) from the Fauve de Bourgogne strain aged 2 to 3 months (CEGAV, Saint-Mars-d'Egrenne, France) were used in this study. All animals were treated according to the Directive 2010/63/UE European Convention for the Protection of Vertebrate Animals used for Experimental and Other Scientific Purposes and to the Association for Research in Vision and Ophthalmology (ARVO) statement for the Use of Animals in Ophthalmic and Vision Research. The duration of the biological effect of DXP nanoparticles was assessed at time-points up to 2 months (time points were 1 week, 1 and 2 months). Pigmented rabbits were dosed (50 $\mathrm{L}$, once) with unilateral intravitreal injections of $0.8 \%(400 \mu \mathrm{g}) \mathrm{DXP}$ nanoparticles. Breakdown of the blood-retinal barrier (BRB) of the treated eyes was induced at each predefined time point by a single $50 \mu \mathrm{l} \mathrm{IVT} \mathrm{injection} \mathrm{of} 500$ ng rhVEGF165 with carrier protein (diluted in PBS). Forty-eight hours after the induction, sodium fluorescein leakage was quantified with a FM-2 Fluorotron Master ocular photometer (OcuMetrics, Mountain View, CA, USA). The efficacy of the DXP nanoparticles was determined by comparing the fluorescein leakage of the treated eyes with the untreated contralateral eye. A ratio close to 1 (treated right eye vs untreated unchallenged left eye) was indicative of the restoration of the integrity of the BRB.

\section{RESULTS AND DISCUSSION}

DXP photostability was assessed as described above and revealed a degradation of about $90 \%$ of DXP with purity decreasing from $99.1 \%$ to $8.5 \%$. Amber glasseware was therefore used for the remaining of the experiments. Three surfactants were considered for DXP nanoparticle stabilization all bearing PEG moieties that are important for steric stabilization of nanoparticles(Lorscheider et al., 2019a) : PEG-40-stearate (P-40) and Pluronic block copolymers F68 and F127. These were chosen for their compatibility with an intravitreous injection due to their low ocular toxicity(Dumortier et al., 2006). Numerous formulations were tested with different concentrations of surfactant and DXP to isolate the optimal one. In each case, three concentrations of surfactant $(1.0,1.5$ and $2.0 \% \mathrm{w} / \mathrm{v})$ were tested with two or three concentrations of DXP $(0.025,0.050$ and $0.075 \% \mathrm{w} / \mathrm{v})$. In particular, we were interested in the size and polydispersity evolution with time, as well as the crystallinity. Indeed, DXP is prone to crystallize and DXP NPs may undergo Ostwald ripening. Preliminary 
experiments showed that the presence of $0.9 \% \mathrm{NaCl}(\mathrm{w} / \mathrm{w})$ was beneficial for preventing crystallization. The first round of experiments was therefore carried out keeping $\mathrm{NaCl}$ concentration constant at $0.9 \%(\mathrm{w} / \mathrm{v})$. The influence of $\mathrm{NaCl}$, as well as the storage temperature, were tested in a second time, on the optimized formulation only.

\section{Choice of surfactant}

\subsection{PEG-40-stearate}

Results obtained using PEG-40-stearate as a stabilizer are shown in figure 1 . The average size of the particles was generally higher than $100 \mathrm{~nm}$, and PDIs between 0.28 and 0.5 indicate high polydispersity. The higher the P-40 concentration, the more stable the size over time. The higher the DXP concentration, the faster nanoparticle size increases, in agreement with the turbidity observed visually after 2 or 5 days. Aggregates/precipitates observed by optical microscopy correspond to DXP crystals therefore confirming the importance of Ostwald ripening(Boissenot et al., 2016; Gomez-Gaete et al., 2007; Gómez-Gaete et al., 2008; Teeranachaideekul et al., 2008). Although the stearate moiety of P-40 could theoretically interact with the palmitate moiety of DXP, the presence of the dexamethasone moiety on DXP prevents interaction most probably by steric hindrance. Given these results, $\mathrm{P}-40$ cannot be considered as a good stabilizer for DXP nanoparticles.

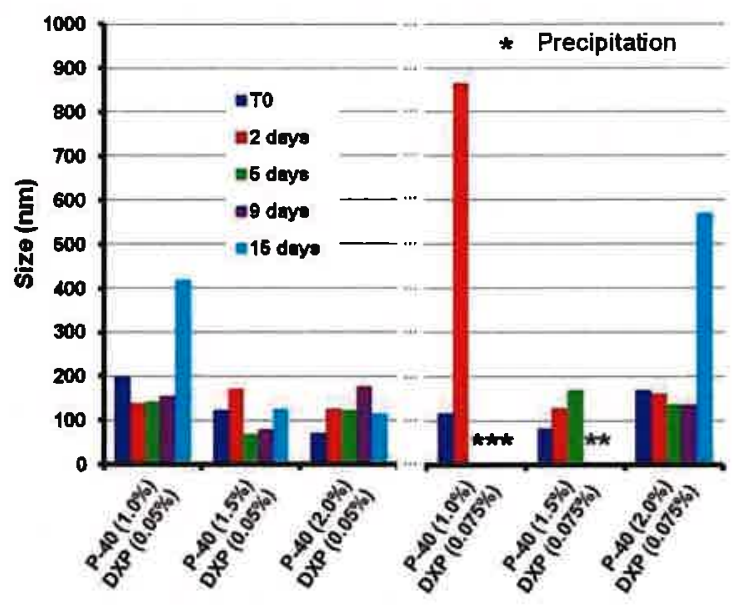

Figure 1: Size of DXP nanoparticles prepared with PEG-Stearate P-40 as a function of time upon storage at room temperature $(n=3)$.

\subsection{Pluronic F68}

F68 was the worst of the three surfactants investigated for stabilization of DXP NPs. Even with DXP concentration as low as $0.025 \%(w / v)$, suspensions were already slightly turbid at T0 and turbidity went increasing as the size increased. DXP NP size initially around $50 \mathrm{~nm}$ increased above $100 \mathrm{~nm}$ with PDIs between 0.03 and 0.3 within two days of preparation and 
kept increasing afterwards until aggregation/precipitation (Figure 2). Aggregates/precipitates observed by optical microscopy correspond to DXP crystals therefore confirming the importance of Ostwald ripening. Given the poor stability of the suspensions, Pluronic F68 was unable to stabilize DXP NPs and should not be considered further.

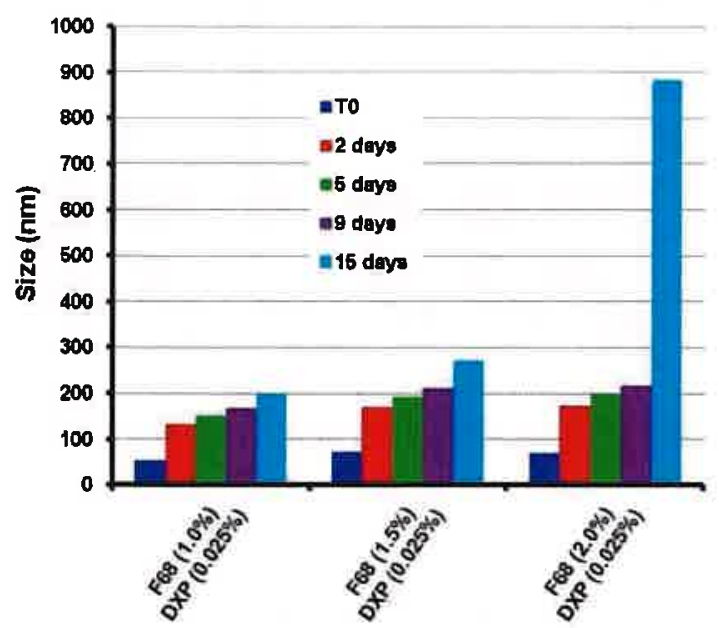

Figure 2: Size of DXP NPs prepared with Pluronic F68 as a function of time upon storage at room temperature $(n=3)$.

\subsection{Pluronic F127}

The best results were obtained using Pluronic F127. The formulations prepared with DXP at $0.05 \%(\mathrm{w} / \mathrm{v})$ and F127 concentrations 1.5 and $2.0 \%(\mathrm{w} / \mathrm{v})$ remained stable and transparent for 15 days. In both cases, the average size of the NPs remained unchanged, around $40 \mathrm{~nm}$ with PDIs between 0.12 and 0.27 . When DXP concentration was increased to $0.075 \%(\mathrm{w} / \mathrm{v})$, the suspension prepared with $\mathrm{F} 127$ at $1.5 \%(\mathrm{w} / \mathrm{v})$ was totally stable and transparent during at least 9 days. The average size of the particles remained around $40 \mathrm{~nm}$ with PDIs between 0.13 and 0.16 (Figure 3). As for P-40, we observe that the higher the surfactant concentration, the better the stabilization. One can also note that the higher the DXP concentration, the more prone to aggregation/precipitation of the suspension. As for other surfactants, aggregates/precipitates observed by optical microscopy correspond to DXP crystals confirming the importance of Ostwald ripening in the destabilization process.

Pluronic F127 indeed appears as the best surfactant to stabilize tiny DXP NPs with a low polydispersity. The better stabilization probably arises from the steric repulsions of longer PEG moieties of Pluronic F127 as compared with Pluronic F68 or PEG-40 stearate. As a compromise between stability of the suspension and DXP concentration, we have chosen to pursue our study using DXP NPs prepared with $1.5 \%$ (w/v) F127 and $0.075 \%$ (w/v) DXP. 


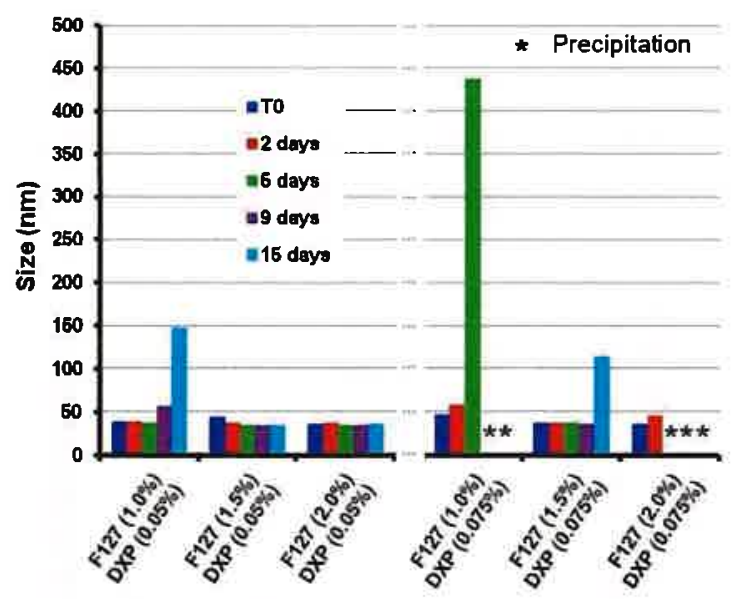

Figure 3: Size of DXP nanoparticles prepared with Pluronic F127 as a function of time upon storage at room temperature

Another nanoparticulate system containing DXP was previously described by Lu et al. (Lu et al., 2008) and Kim et al.(Kim et al., 2011). The process reported, called 'nanotemplate engineering', consists in a microemulsion formed by a melted matrix material (oil phase) combined with a mixture of water and surfactants. DXP is solubilized in the oil phase which forms a suspension of solid NPs during the cooling of the microemulsion to room temperature. The maximum drug concentration obtained was $0.48 \mathrm{mg} / \mathrm{mL}$, with an average size of the NPs around 90 to $130 \mathrm{~nm}$, and Ostwald ripening was also observed. Our formulation is then 1.5 times more concentrated $(0.75 \mathrm{mg} / \mathrm{mL})$, with an average size 3 to 4 times smaller, exhibiting a low opacity (light transmission at $850 \mathrm{~nm}=99.5 \%$ ).

\section{Characterization and optimization of the formulation}

For intravitreal injections, in the literature doses of $700 \mu \mathrm{g}$ or $350 \mu \mathrm{g}$ of DXM are reported for human(Boyer et al., 2011; "Dexamethasone: intravitreal implant," 2011; Haller et al., 2011; Zucchiatti et al., 2012), corresponding to $1125 \mu \mathrm{g}$ and $563 \mu \mathrm{g}$ DXP respectively. Since patients usually receive a $100 \mu \mathrm{L}$ intravitreal injection, DXP concentration should be around $8 \mathrm{mg} / \mathrm{mL}$ (i.e. $0.8 \%(w / v))$. To further concentrate DXP NPs, we used a ultrafiltration cell fitted up with a $100,000 \mathrm{kDa}$ regenerated cellulose membrane under nitrogen pressure until the volume was reduced to one tenth. In addition, this process reduced the proportion of Pluronic F127 since the surfactant passes through the membrane while the nanoparticles did not. Obviously, the concentrated suspension was less stable than the diluted one ( 3 days) but the size just after ultrafiltration was exactly the same, around $35 \mathrm{~nm}$ with a PDI of 0.07 . The concentration of DXP was checked via HPLC in the concentrated suspension and in the filtrate to be sure that 
NPs were blocked by the membrane. Results are presented in table 2. In addition, opacity remained low for the concentrated suspension (light transmission at $850 \mathrm{~nm}$ was $96.1 \%$ ).

Table 2: Characteristics of the diluted and concentrated suspension in terms of DXP concentration.

\begin{tabular}{cc}
\hline Formulation & F127 (1.5\%) / DXP (0.075 \%) \\
\hline $\begin{array}{c}\text { Average } C_{\text {Dxp }} \text { in the diluted } \\
\text { suspension }(\mu \mathrm{g} / \mathrm{mL})\end{array}$ & $745 \pm 27$ \\
\hline $\begin{array}{c}\text { Average } C_{\text {DXP }} \text { in the } \\
\text { concentrated suspension } \\
(\mu \mathrm{g} / \mathrm{mL})\end{array}$ & $7520 \pm 800$ \\
$\begin{array}{c}\text { Average } \mathrm{C}_{\mathrm{DXP}} \text { free in the } \\
\text { filtrate }(\mu \mathrm{g} / \mathrm{mL})\end{array}$ & $7.4 \pm 0.2$ \\
Efficacy of encapsulation $(\%)$ & 99 \\
\hline
\end{tabular}

Nanoparticle storage was then evaluated on the optimal formulation. Nanoparticles could not be stored at $4^{\circ} \mathrm{C}$ without precipitation contrary to what was observed with PEGylated lipids nanoparticles(Lorscheider et al., 2019a). This happens most probably due to a transition of F127 from micelles to unimers as temperature decreases(Alexandridis and Hatton, 1995). In a hypothetical industrial development, the final product has to be storable during weeks or months without changes. The second option was to freeze-dry the suspensions after addition of trehalose as a cryoprotectant. Different concentrations of trehalose were tested to assess the lowest concentration necessary to yield easy to resuspend lyophilisates without modifying DXP NP characteristics. Results presented in table 3 show that $2.5 \%$ of trehalose is enough to protect nanoparticles during the freeze-drying process.

Table 3: Size and PDI of initial and freeze-dried supensions as a function of trehalose content.

\begin{tabular}{ccc|}
\hline & $\begin{array}{c}\text { Size } \pm \text { S.D. } \\
(\mathrm{nm})\end{array}$ & PDI \\
\hline $\begin{array}{c}\text { Trehalose } \\
\text { \% }\end{array}$ & $36 \pm 0.5$ & 0.11 \\
\hline $\begin{array}{c}\text { Trehalose 1.0 } \\
\text { \% }\end{array}$ & $172 \pm 7.8$ & 0.58 \\
\hline $\begin{array}{c}\text { Trehalose 2.5 } \\
\text { \% }\end{array}$ & $212 \pm 8.2$ & 0.42 \\
\hline $\begin{array}{c}\text { Trehalose 3.5 } \\
\text { \% }\end{array}$ & $35 \pm 0.06$ & 0.07 \\
\hline $\begin{array}{c}\text { Trehalose 4.5 } \\
\text { \% }\end{array}$ & $36 \pm 0.08$ & 0.06 \\
\hline
\end{tabular}


Osmolality

The influence of sodium chloride concentration was checked on the optimized formulation by measuring the osmolality of the suspension. At the beginning, nanoparticles were prepared with $0.9 \%$ of $\mathrm{NaCl}$. This is the usual concentration used to avoid osmotic shock. The problem was that, for the suspension freeze-dried with $2.5 \%$ of trehalose and $0.9 \%$ of $\mathrm{NaCl}$, the osmolality was measured at $1090 \mathrm{mOsmol} . \mathrm{kg}^{-1}$ after redispersion at $0.8 \%$ of DXP. The average size of these resuspended nanoparticles remained $35 \mathrm{~nm}$ with a PDI of 0.05 after 7 days, but that high osmolality was problematic for injection. In the same conditions but without sodium chloride, it was measured at 550 mOsmol. $\mathrm{kg}^{-1}$, meaning that nanoparticles themselves induce a significant osmolality. The average size of the NPs prepared without $\mathrm{NaCl}$ was $36 \mathrm{~nm}$ with a PDI of 0.1 , with a negative zeta potential $(-4.25 \pm 0.9 \mathrm{mV}, n=3)$. The opacity of the resuspended nanoparticles remained low (light transmission at $850 \mathrm{~nm}$ was $96 \%$ ).

\section{X-Ray Powder Diffraction (XRPD)}

To the best of our knowledge, only one paper deals with the crystallographic structure of DXP(Doi et al., 1989). Doi et al. described two polymorphic crystalline forms of DXP obtained by crystallization in acetone or in $n$-heptane. X-Ray Powder Diffraction was performed on F127, DXP crystallized in acetone (thin needles-like crystals) and freeze-dried nanoparticles. XRPD of the DXP crystals obtained from acetone exhibit the characteristic diffraction peaks of a monoclinic unit cell (Green line, Figure 4). Experiments also reveal that no characteristic diffraction peaks of DXP crystals were present on the powder pattern of a freshly lyophilisate sample of DXP nanoparticles (Red line, Figure 4). DXP nanoparticles are therefore amorphous. The Bragg peaks observed at $2 \theta=19.2^{\circ}$ and $23.4^{\circ}$, and the broad peaks observed at $2 \theta=26.5^{\circ}, 36^{\circ}$ and $39.5^{\circ}$ are characteristic of lyophilized Pluronic F127 (Black line, Figure 4)(Lian et al., 2011). Trehalose added to the formulation before freeze-drying is also amorphous and is responsible for the flattening of the bump situated between 7 and $15^{\circ}$ observable for F127.

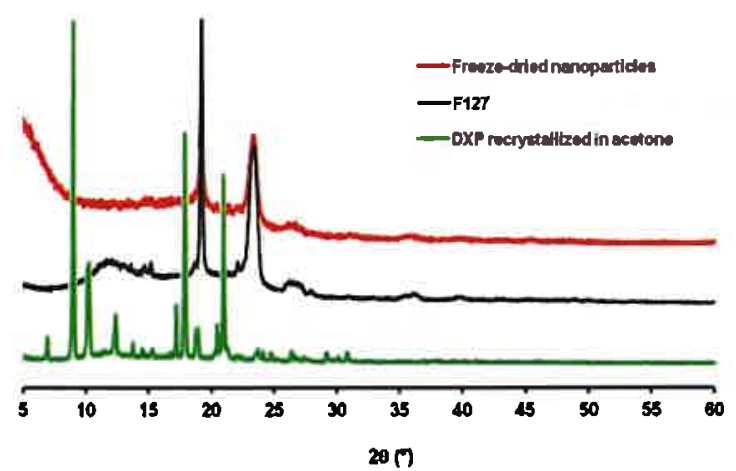

Figure 4: XRPD patterns of freeze-dried nanoparticles (Red line), freeze-dried Pluronic F127 (Black line), and DXP crystallized in acetone (Green line). 
TEM

TEM images of the DXP NPs diluted at $0.2 \mathrm{mg} / \mathrm{mL}$ (Fig $5 \mathrm{~A}$ ) and at $0.04 \mathrm{mg} / \mathrm{mL}$ (Fig 5B) are in agreement with the DLS results mentioned above. The nanoparticles appeared monodisperse and rather spherical with an average size around $25 \mathrm{~nm}$ in agreement with DLS measurements. A Fast Fourier Transform (FFT) of Figure 5A image was performed and confirms that DXP NPs are amorphous as no pattern was observed.
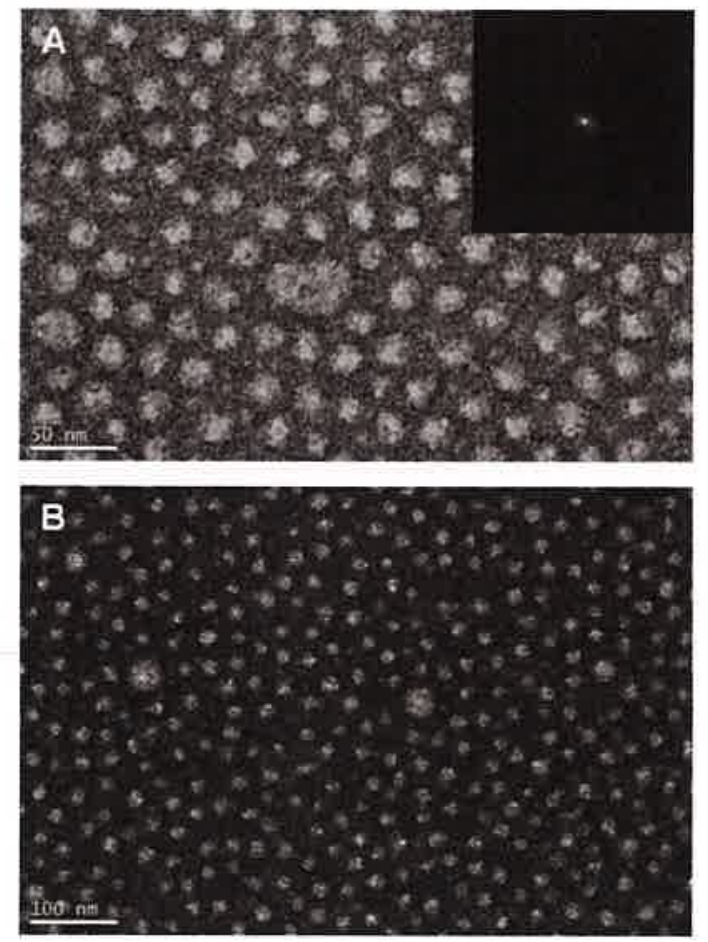

Figure 5: TEM images of the DXP NPs at $0.2 \mathrm{mg} / \mathrm{mL}(A)$ and at $0.04 \mathrm{mg} / \mathrm{mL}$ (B). The inset corresponds to the image A FFT.

These optimized DXP NPs therefore possess all the characteristics suited for intravitreal injection and were administered in vivo.

\section{In vivo results}

After DXP NP intravitreal injection, 8 out of 10 animals $(8 / 10)$ and $9 / 9$ and $2 / 9$, presented a restoration of the blood-retinal barrier at one week and one and two months, respectively, as attested by a markedly reduced fluorescein leakage in the eye after intravenous injection (Fig 6). These results demonstrate that a single DXP NP injection was able to deliver DXM to the tissues of the posterior segment of the eye at a concentration sufficient to normalize VEGFinduced vascular hyperpermeability for one month. However, two months after DXP NP 
intravitreal injection, the blood-retinal barrier was leaky again, suggesting a relatively rapid clearance of the DXP NPs that can be attributed to their small size $(35 \mathrm{~nm})$.

Fluorescein leakage

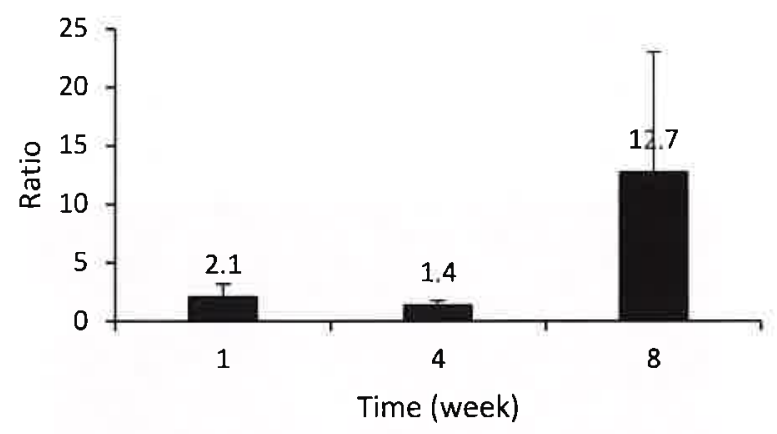

Figure 6: Fluorescein leakage over time following a single intravitreal injection of DXP NPs.

These results should be compared to an intravitreal injection of DXM solution that has a halflife of about 3 hours only(Graham and Peyman, 1974). Indeed, molecules of molecular weight lower than $500 \mathrm{Da}$, presented in the form of a solution require frequent administrations, owing to a limited retention half-life of approximately 3 days(Thrimawithana et al., 2011). Bourges et al. described the benefits of intravitreal administration of NPs over drug solutions in targeting of the retina, thus directing our development toward this dosage form(Bourges et al., 2003). In addition, NP size and charge have a major impact on the vitreous clearance rate. The smaller the size, the faster the elimination, but bigger size particles may sediment and provoke visual disturbance when suspended in the visual field. Thus, to be able to obtain a long-term efficacy with dispersed formulations, a compromise should be found between particle size (i.e. elimination rate) and the visual disturbance.

It is particularly difficult to predict the pharmacokinetics of intravitreal drug as the vitreous which is composed of more than $95 \%$ of water by weight and glycosylaminoglycans can vary in density and viscosity over age, species and disease state. Indeed, vitreous body which has a gel-like structure in young and healthy adults becomes more fluid in inflamed conditions and older adults(Kleinberg et al., 2011).

\section{CONCLUSION}

DXP formulation into tiny nanoparticles was optimized for intravitreal injection. For the first time, these nanoparticles were concentrated to reach the therapeutically level needed for ocular delivery directly after the nanoprecipitation with Pluronic F127 as stabilizer, or by resuspension from freeze-dried samples. In both cases, NP size was around $35 \mathrm{~nm}$, allowing 
a low opacity, with a negative zeta potential around $-4 \mathrm{mV}$. XRPD and TEM experiments revealed that the nanoparticles were amorphous and monodisperse, and HPLC tests confirmed a $99 \%$ encapsulation efficacy. In vivo experiments performed in rabbits revealed the ability of DXP NPs to restore the blood retinal barrier up to one month after injection. However, the effect of blood-retinal barrier restoration did not last two months after DXP NP intravitreal injection, proving rapid clearance of the DXP NPs given their small size. A reservoir of DXP NP might represent an interesting alternative to prolong their effect.

\section{ACKNOWLEDGEMENTS}

This research received support from CNRS. The present work has benefited from Imagerie-Gif core facility supported by l'Agence Nationale de la Recherche (ANR-11-EQPX0029/Morphoscope, ANR-10-INBS-04/FranceBiolmaging; ANR-11-IDEX-0003-02/ Saclay Plant Sciences) with the precious help of $C$. Boulogne. Authors would like to acknowledge fruitful discussions with F. Agnely. Servier Medical Art is acknowledged for the rabbit illustration.

\section{REFERENCES}

(AAO), A.A. of O., 2006. Age-Related Macular Degeneration, Preferred Practice Pattern: Limited Revision. San Francisco, CA: American Academy of Ophthalmology.

Alexandridis, P., Hatton, T.A., 1995. Poly(Ethylene Oxide)-Poly(Propylene Oxide)Poly(Ethylene Oxide) Block-Copolymer Surfactants in Aqueous-Solutions and at Interfaces - Thermodynamics, Structure, Dynamics, and Modeling. Colloids Surfaces aPhysicochemical Eng. Asp. 96, 1-46.

Allen, T.M., Cleland, L.G., 1980. Serum-induced leakage of liposome contents. BBA Biomembr. 597, 418-426. https://doi.org/10.1016/0005-2736(80)90118-2

Allen, T.M., Cullis, P.R., 2013. Liposomal drug delivery systems: From concept to clinical applications. Adv. Drug Deliv. Rev. 65, 36-48. https://doi.org/10.1016/j.addr.2012.09.037

Bochot, A., Fattal, E., 2012. Liposomes for intravitreal drug delivery: A state of the art. J. Control. Release. https://doi.org/10.1016/j.jconrel.2012.01.019 
Boissenot, T., Fattal, E., Bordat, A., Houvenagel, S., Valette, J., Chacun, H., Gueutin, C., Tsapis, N., 2016. Paclitaxel-loaded PEGylated nanocapsules of perfluorooctyl bromide as theranostic agents. Eur. J. Pharm. Biopharm. 108, 136-144.

https://doi.org/10.1016/j.ejpb.2016.08.017

Bourges, J.L., Gautier, S.E., Delie, F., Bejjani, R.A., Jeanny, J.C., Gurny, R., BenEzra, D., Behar-Cohen, F.F., 2003. Ocular drug delivery targeting the retina and retinal pigment epithelium using polylactide nanoparticles. Invest Ophthalmol Vis Sci 44, 3562-3569.

Boyer, D.S., Faber, D., Gupta, S., Patel, S.S., Tabandeh, H., Li, X.Y., Liu, C.C., Lou, J., Whitcup, S.M., 2011. Dexamethasone intravitreal implant for treatment of diabetic macular edema in vitrectomized patients. Retina 31, 915-923.

https://doi.org/10.1097//AE.0b013e318206d18c

Buschini, E., Piras, A., Nuzzi, R., Vercelli, A., 2011. Age related macular degeneration and drusen: Neuroinflammation in the retina. Prog. Neurobiol. 95, 14-25.

de Kozak, Y., Andrieux, K., Villarroya, H., Klein, C., Thillaye-Goldenberg, B., Naud, M.C., Garcia, E., Couvreur, P., 2004. Intraocular injection of tamoxifen-loaded nanoparticles: a new treatment of experimental autoimmune uveoretinitis. Eur J Immunol 34, 37023712. https://doi.org/10.1002/eji.200425022

Dexamethasone: intravitreal implant, 2011. . Prescrire Int 20, 178-179.

Doi, M., Ishida, T., Sugio, S., Imagawa, T., Inoue, M., 1989. Physicochemical properties of dexamethasone palmitate, a high fatty acid ester of an anti-inflammatory drug: polymorphism and crystal structure. J. Pharm. Sci. 78, 417-22.

Dumortier, G., Grossiord, J.L., Agnely, F., Chaumeil, J.C., 2006. A review of poloxamer 407 pharmaceutical and pharmacological characteristics. Pharm Res 23, 2709-2728. https://doi.org/10.1007/s11095-006-9104-4

Fattal, E., Lorscheider, M., Tsapis, N., Reynaud, F., Canioni, R., 2018. Nanoparticulate prodrugs. WO 2018/054953 A1.

Ferrante, P., Ramsey, A., Bunce, C., Lightman, S., 2004. Clinical trial to compare efficacy and side-effects of injection of posterior sub-Tenon triamcinolone versus orbital floor methylprednisolone in the management of posterior uveitis. Clin Exp. Ophthalmol 32, 563-568. https://doi.org/CEO902 [pii]10.1111/j.1442-9071.2004.00902.x

Fessi, H., Puisieux, F., Devissaguet, J.P., Ammoury, N., Benita, S., 1989. Nanocapsule formation by interfacial polymer deposition following solvent displacement. Int. J. Pharm. 55, R1-R4. https://doi.org/10.1016/0378-5173(89)90281-0 
Giancipoli, E., Pinna, A., Boscia, F., Zasa, G., Sotgiu, G., Dore, S., D’Amico Ricci, G., 2018. Intravitreal Dexamethasone in Patients with Wet Age-Related Macular Degeneration Resistant to Anti-VEGF: A Prospective Pilot Study. J. Ophthalmol. 2018. https://doi.org/10.1155/2018/5612342

Gomes dos Santos, A.L.L., Bochot, A., Doyle, A., Tsapis, N., Siepmann, J., Siepmann, F., Schmaler, J., Besnard, M., Behar-Cohen, F., Fattal, E., 2006. Sustained release of nanosized complexes of polyethylenimine and anti-TGF-beta 2 oligonucleotide improves the outcome of glaucoma surgery. J Control Release 112, 369-381. https://doi.org/S0168-3659(06)00078-2 [pii]10.1016/j.jconrel.2006.02.010

Gomes Dos Santos, A.L.L., Bochot, A., Tsapis, N., Artzner, F., Bejjani, R.A.A., ThillayeGoldenberg, B., de Kozak, Y., Fattal, E., Behar-Cohen, F., 2006. Oligonucleotidepolyethylenimine complexes targeting retinal cells: structural analysis and application to anti-TGFbeta-2 therapy. Pharm Res 23, 770-781. https://doi.org/10.1007/s11095-0069748-0

Gómez-Gaete, C., Fattal, E., Silva, L., Besnard, M., Tsapis, N., Gomez-Gaete, C., Fattal, E., Silva, L., Besnard, M., Tsapis, N., 2008. Dexamethasone acetate encapsulation into Trojan particles. J Control Release 128, 41-49. https://doi.org/10.1016/j.jconrel.2008.02.00850168-3659(08)00098-9 [pii]

Gomez-Gaete, C., Tsapis, N., Besnard, M., Bochot, A., Fattal, E., Gómez-Gaete, C., Tsapis, N., Besnard, M., Bochot, A., Fattal, E., 2007. Encapsulation of dexamethasone into biodegradable polymeric nanoparticles. Int J Pharm 331, 153-159. https://doi.org/S0378-5173(06)00985-9 [pii]10.1016/j.jpharm.2006.11.028

Graham, R.O., Peyman, G.A., 1974. Intravitreal injection of dexamethasone. Treatment of experimentally induced endophthalmitis. Arch Ophthalmol 92, 149-154.

Grzybowski, A., Brockmann, T., Kanclerz, P., Pleyer, U., 2019. Dexamethasone Intraocular Suspension: A Long-Acting Therapeutic for Treating Inflammation Associated with Cataract Surgery. J. Ocul. Pharmacol. Ther. https://doi.org/10.1089/jop.2019.0072

Haller, J.A., Bandello, F., Belfort Jr., R., Blumenkranz, M.S., Gillies, M., Heier, J., Loewenstein, A., Yoon, Y.H., Jiao, J., Li, X.Y., Whitcup, S.M., Li, J., 2011. Dexamethasone intravitreal implant in patients with macular edema related to branch or central retinal vein occlusion twelve-month study results. Ophthalmology $118,2453-$ 2460. https://doi.org/S0161-6420(11)00457-X [pii]10.1016/j.ophtha.2011.05.014

Irache, J.M., Merodio, M., Arnedo, A., Camapanero, M.A., Mirshahi, M., Espuelas, S., 2005. Albumin nanoparticles for the intravitreal delivery of anticytomegaloviral drugs. Mini Rev 
Med Chem 5, 293-305.

Ishihara, T., Takahashi, M., Higaki, M., Mizushima, Y., 2009. Efficient encapsulation of a water-soluble corticosteroid in biodegradable nanoparticles. Int. J. Pharm. 365, 200205. https://doi.org/DOI 10.1016/j.jpharm.2008.08.030

Ishihara, T., Takahashi, M., Higaki, M., Mizushima, Y., Mizushima, T., 2010. Preparation and characterization of a nanoparticulate formulation composed of PEG-PLA and PLA as anti-inflammatory agents. Int. J. Pharm. 385, 170-175. https://doi.org/DOI 10.1016/j.ijpharm.2009.10.025

Kassem, M.A., Abdel Rahman, A.A., Ghorab, M.M., Ahmed, M.B., Khalil, R.M., 2007. Nanosuspension as an ophthalmic delivery system for certain glucocorticoid drugs. Int $\mathrm{J}$ Pharm 340, 126-133. https://doi.org/S0378-5173(07)00244-X [pii]10.1016/j.jpharm.2007.03.011

Kertes, P.J., Coupland, S.G., 2005. The use of subretinal triamcinolone acetonide in the management of neovascular age-related macular degeneration: a pilot study. Can J Ophthalmol 40, 573-584. https://doi.org/S0008-4182(05)80049-3 [pii]10.1016/S00084182(05)80049-3

Kim, D.H., Martin, D.C., 2006. Sustained release of dexamethasone from hydrophilic matrices using PLGA nanoparticles for neural drug delivery. Biomaterials 27, 30313037. https://doi.org/S0142-9612(06)00004-4 [pii]10.1016/j.biomaterials.2005.12.021

Kim, J.K., Howard, M.D., Dziubla, T.D., Rinehart, J.J., Jay, M., Lu, X., 2011. Uniformity of drug payload and its effect on stability of solid lipid nanoparticles containing an ester prodrug. ACS Nano 5, 209-216. https://doi.org/10.1021/nn102357y

Kleinberg, T.T., Tzekov, R.T., Stein, L., Ravi, N., Kaushal, S., 2011. MAJOR REVIEW Vitreous Substitutes: A Comprehensive Review. Surv. Ophthalmol. 56, 300-323. https://doi.org/10.1016/j.survophthal.2010.09.001

Kokotas, H., Grigoriadou, M., Petersen, M.B., 2011. Age-related macular degeneration: genetic and clinical findings. Clin Chem Lab Med 49, 601-616. https://doi.org/10.1515/CCLM.2011.091

Kumari, A., Yadav, S.K., Yadav, S.C., 2010. Biodegradable polymeric nanoparticles based drug delivery systems. Colloids Surfaces B Biointerfaces 75, 1-18. https://doi.org/10.1016/J.COLSURFB.2009.09.001

Kwak, H.W., D'Amico, D.J., 1992. Evaluation of the retinal toxicity and pharmacokinetics of dexamethasone after intravitreal injection. Arch Ophthalmol 110, 259-266. 
Lian, R., Lu, Y., Qi, J., Tan, Y., Niu, M., Guan, P., Hu, F., Wu, W., 2011. Silymarin glyceryl monooleate/poloxamer 407 liquid crystalline matrices: physical characterization and enhanced oral bioavailability. AAPS PharmSciTech 12, 1234-1240.

https://doi.org/10.1208/s12249-011-9666-2

Lorscheider, M., Tsapis, N., Simón-Vázquez, R., Guiblin, N., Ghermani, N., Reynaud, F., Canioni, R., Abreu, S., Chaminade, P., Fattal, E., 2019a. Nanoscale Lipophilic Prodrugs of Dexamethasone with Enhanced Pharmacokinetics. Mol. Pharm. 16, 2999-3010. https://doi.org/10.1021/acs.molpharmaceut.9b00237

Lorscheider, M., Tsapis, N., Ur-Rehman, M., Gaudin, F., Stolfa, I., Abreu, S., Mura, S., Chaminade, P., Espeli, M., Fattal, E., Mujeeb-ur-Rehman, Gaudin, F., Stolfa, I., Abreu, S., Mura, S., Chaminade, P., Espeli, M., Fattal, E., 2019b. Dexamethasone palmitate nanoparticles: An efficient treatment for rheumatoid arthritis. J. Control. Release 296, 179-189. https://doi.org/10.1016/J.JCONREL.2019.01.015

Lu, X., Howard, M.D., Mazik, M., Eldridge, J., Rinehart, J.J., Jay, M., Leggas, M., 2008. Nanoparticles containing anti-inflammatory agents as chemotherapy adjuvants: optimization and in vitro characterization. AAPS J. 10, 133-140. https://doi.org/10.1208/s12248-008-9013-z

Malclès, A., Janin-Manificat, H., Yhuel, Y., Russo, A., Agard, E., El Chehab, H., Ract Madoux, G., Masse, H., Burillon, C., Dot, C., 2013. Migration en chambre antérieure de l'implant intravitréen de dexaméthasone Ozurdex® chez le pseudophake: À propos de trois cas. J. Fr. Ophtalmol. 36, 362-367. https://doi.org/10.1016/j.jfo.2012.11.003

Merodio, M., Irache, J.M., Valamanesh, F., Mirshahi, M., 2002. Ocular disposition and tolerance of ganciclovir-loaded albumin nanoparticles after intravitreal injection in rats. Biomaterials 23, 1587-1594. https://doi.org/S0142961201002848 [pii]

Mitchell, P., Liew, G., Gopinath, B., Wong, T.Y., 2018. Age-related macular degeneration. Lancet. https://doi.org/10.1016/S0140-6736(18)31550-2

Munoz-Fernandez, S., Martin-Mola, E., 2006. Uveitis. Best Pr. Res Clin Rheumatol 20, 487505. https://doi.org/S1521-6942(06)00038-6 [pii]10.1016/j.berh.2006.03.008

Rein, D.B., Wittenborn, J.S., Zhang, X., Honeycutt, A.A., Lesesne, S.B., Saaddine, J., 2009. Forecasting age-related macular degeneration through the year 2050: the potential impact of new treatments. Arch Ophthalmol 127, 533-540. https://doi.org/127/4/533 [pii]10.1001/archophthalmol.2009.58

Sahoo, S.K., Dilnawaz, F., Krishnakumar, S., 2008. Nanotechnology in ocular drug delivery. Drug Discov Today 13, 144-151. https://doi.org/S1359-6446(07)00461-8 
[pii]10.1016/j.drudis.2007.10.021

Teeranachaideekul, V., Junyaprasert, V.B., Souto, E.B., M??ller, R.H., 2008. Development of ascorbyl palmitate nanocrystals applying the nanosuspension technology. Int. J. Pharm. 354, 227-234. https://doi.org/10.1016/j.jpharm.2007.11.062

Thrimawithana, T.R., Young, S., Bunt, C.R., Green, C., Alany, R.G., 2011. Drug delivery to the posterior segment of the eye. Drug Discov. Today 16, 270-277. https://doi.org/DOI 10.1016/j.drudis.2010.12.004

Vela, J.I., Crespí, J., Andreu, D., 2012. Repositioning of dexamethasone intravitreal implant (Ozurdex $\otimes$ ) migrated into the anterior chamber. Int. Ophthalmol. 32, 583-584. https://doi.org/10.1007/s10792-012-9604-7

Zucchiatti, I., Lattanzio, R., Querques, G., Querques, L., Del Turco, C., Cascavilla, M.L., Bandello, F., 2012. Intravitreal Dexamethasone Implant in Patients with Persistent Diabetic Macular Edema. Ophthalmologica. https://doi.org/000336225 [pii]10.1159/000336225 